\title{
SIQUEIROS Y LA REVOLUCIÓN
}

\section{IDA RODRÍGUEZ PrampolinI}

La tesis sustentada desde los años cuarenta por David Alfaro Siqueiros: No hay más ruta que la nuestra, pareció y sigue pareciendo una exageración inaceptable a un público que no comparte su sentimiento revolucionario o que, sin analizar las tesis en las que se sustenta su drástica aseveración, la ha interpretado de manera superficial y aislada.

"El movimiento pictórico mexicano moderno, nuestro movimiento, -escribe Siqueiros- es un movimiento que no se ha quedado en la teoría abstracta, sino que desde hace veinte años, viene tocando los primeros escalones de la adecuada práctica. Sin duda alguna, la única posible ruta universal para el próximo futuro". ${ }^{1}$ El nunca separar teoría y práctica revolucionarias es el principio que establece Siqueiros desde el inicio de su carrera, como militante y como artista. En los años cuarenta, fecha en que escribe su texto, eran muy pocas sin embargo, las obras murales que el artista había realizado, de hecho le quedaba todo por hacer.

El descubrimiento de que no hay otra ruta para el arte y para el hombre que la de la revolución está presente desde que Siqueiros redacta el famoso Manifiesto de $1922^{2}$ y a través de todos sus escritos, su obra plástica y su praxis política. Siqueiros tiene una fe en el movimiento artístico y social de México que nunca titubea ni se da por vencido; el camino escogido por los artistas revolucionarios es el único, el justo y el adecuado. Cuando sus compañeros de lucha abandonan la senda o se convierten sólo en compañeros de viaje, él continúa y no desespera porque sabe con certeza que tiene razón. La necesidad social del estilo de Siqueiros y su estética serán por lo tanto entendidos cabalmente sólo si se comprende ése su propósito en la vida: ser un artista, y aún más, el artista ejemplar y salvador del arte y la revolución. ¿Megalomanía, mesianismo, prepotencia, sacrificio, lucha, violencia? Seguramente todo esto y más. Pero así fue Siqueiros.

Siqueiros parte de la convicción de que el artista que produjo la Revolución Mexicana, en un impulso colectivo, con una "teoría vital" de

\footnotetext{
${ }^{1}$ David Alfaro Siqueiros, No hay más ruta que la nuestra. Importancia nacional e internacional de la pintura mexicana moderna. El primer brote de reforma profunda en las artes plásticas del mundo contemporáneo, segunda edición, México, 1978 p. 62.

${ }^{2}$ Declaración social, política y estética. Manifiesto del Sindicato de Pintores, Escultores y Grabadores Revolucionarios de México, firmado por una serie de artistas.
} 
juventud, fue el que encauzó el arte moderno en contraposición al decadente arte europeo por la ruta de un progreso artístico que había sido detenido por la sociedad burguesa. Ese camino, escribió:

con todos los inconvenientes de lo que aún es balbuciente, de lo que aún no ha configurado su propia elocuencia y su propio ademán, pero indudablemente una práctica con un amplio camino por delante... el único camino físico -y estético en consecuencia-, que conduce funcionalmente, en acto de equivalencia social, hacia lo que hoy podemos llamar un nuevo realismo, el nuevo realismo nuevo humanista del presente y del futuro...

Siqueiros cree en el progreso del arte porque cree en el progreso de la humanidad hacia formas superiores de civilización y cultura. No es de extrañar por lo tanto que la obra que cierra el ciclo de su vida la haya titulado al iniciarla, La marcha de la humanidad en la América Latina y al colocarla en forma definitiva en el Polyforum Siqueiros del Hotel de México haya, altisonantemente, modificado el título por el de La marcha de la humanidad en la tierra y hacia el cosmos.

En 1940, convencido Siqueiros de que el muralismo mexicano ha abierto la ruta al progreso del arte universal, y reconociendo el valor de sus compañeros de oficio, especialmente del Dr. Atl, de Orozco y de Rivera, con su obra personal intenta dar un paso más en esa marcha en lucha por encontrar la manifestación plástica que represente su tiempo, identifique a su pueblo y continúe sus luchas. Antes de emprender la nueva etapa del muralismo, Siqueiros analiza con claridad el callejón en el que parece encontrarse de nuevo el arte en México. A pesar de las estrepitosas polémicas públicas que sostuvieron Siqueiros y Diego Rivera, a éste le reconoce haber sido el iniciador del arte de propuestas ideológicas en el mundo moderno, de haber internacionalizado al muralismo y haberle dado validez universal, de haber sabido que el arte público y monumental era el único capaz de volver a dar sentido a la plástica, pero sin embargo, sitúa la obra de Rivera en la primera etapa del muralismo. Lo considera heredero de la manera italiana de concebir la pintura mural y de no haber intentado las técnicas modernas que el mundo tecnológico brinda al artista.

En una carta pública dirigida a su amigo y admirado José Clemente Orozco, en 1944, Siqueiros con verdadera devoción analiza la historia plástica de este artista para reprocharle, en la última parte de la carta,

3 David Alfaro Siqueiros, "La pintura mexicana moderna", Revista Hoy, México, núm. 396, sept. 24, 1944. 


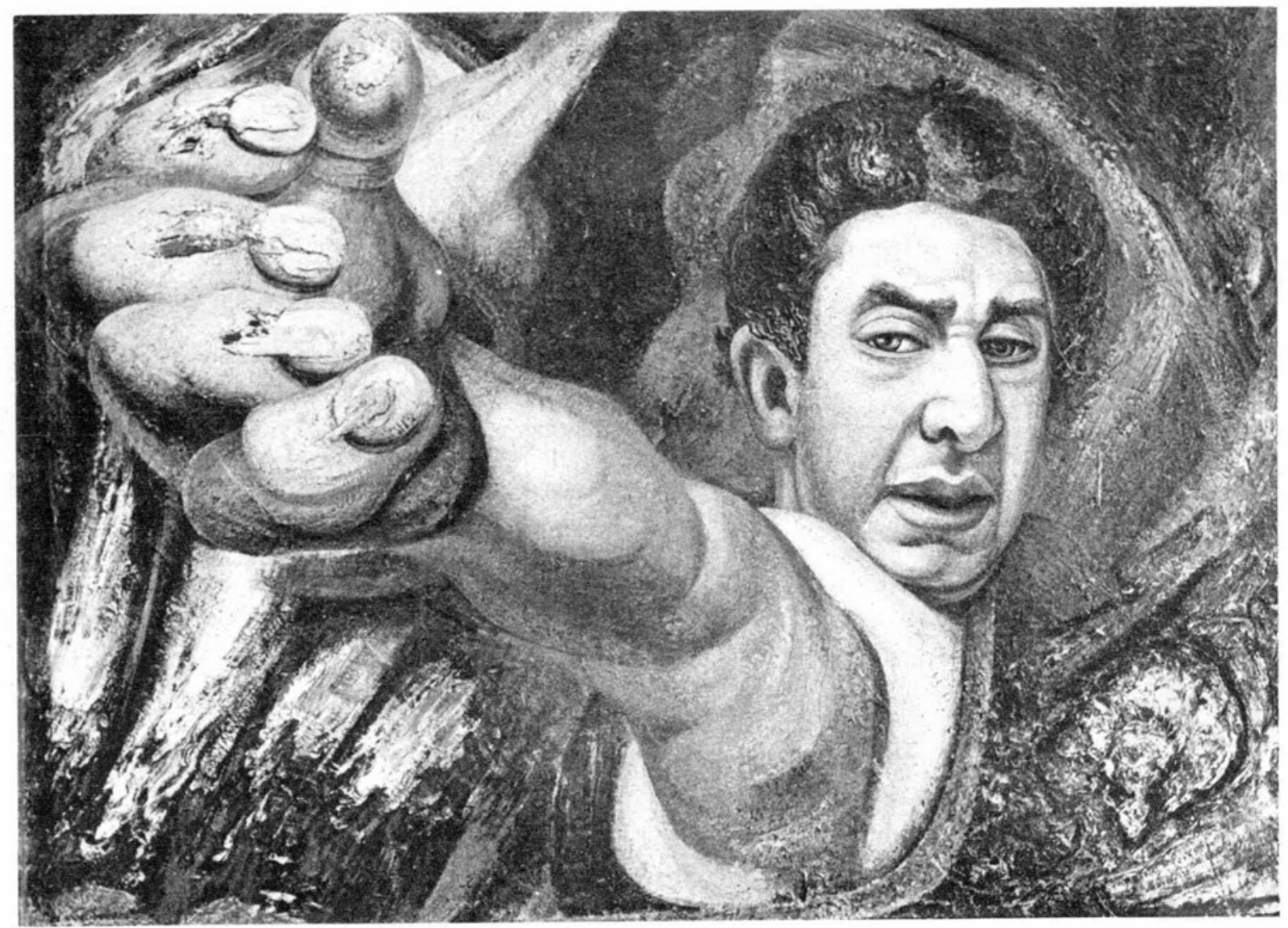

Figura 1. David Alfaro Siqueiros. El Coronelazo. 1945. 
DOI: http://dx.doi.org/10.22201/iie.18703062e.1986.56.1317

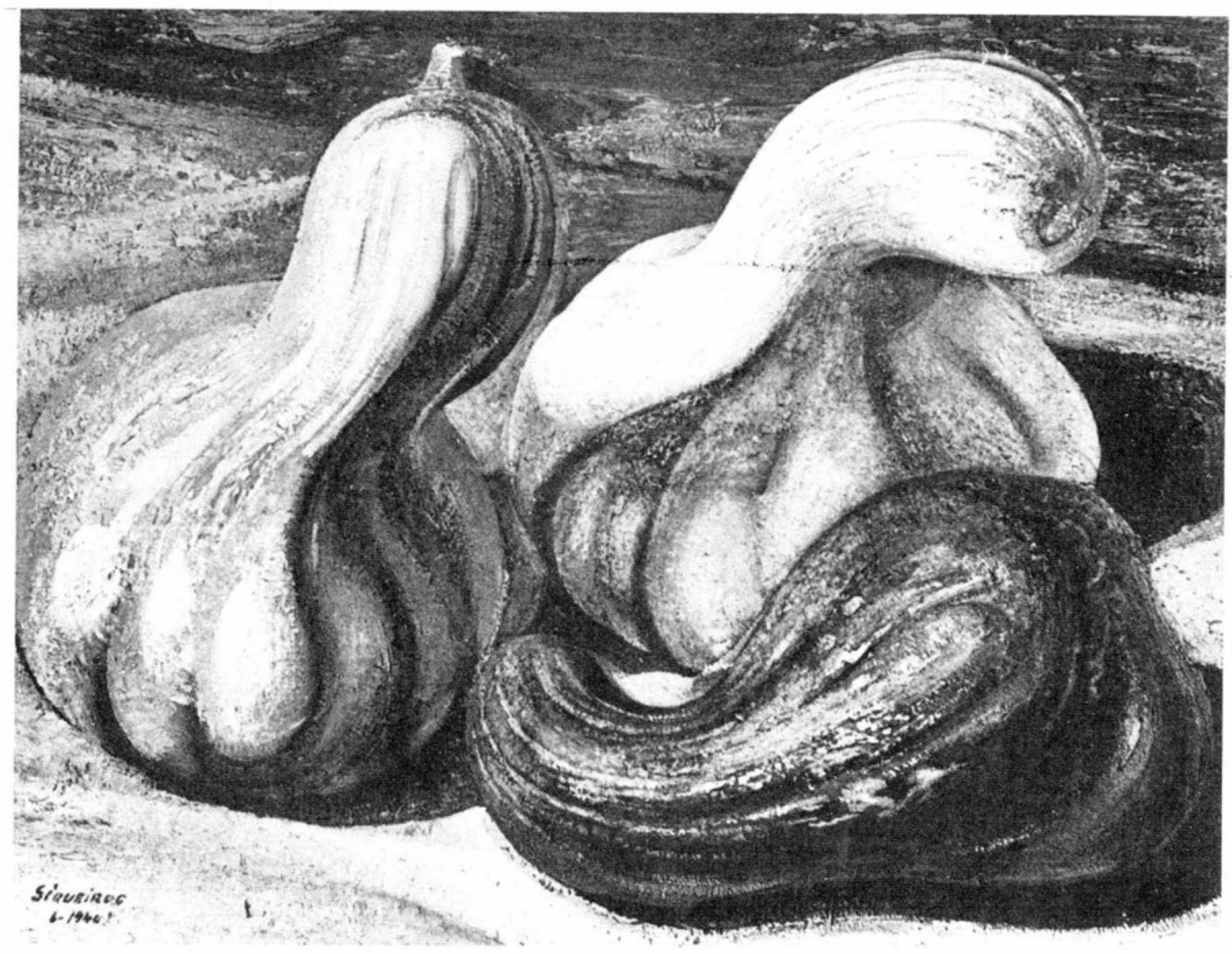

Figura 2. David Alfaro Siqueiros. Calabazas. 1940. 
haber perdido el contacto con el movimiento revolucionario y su práctica en favor de un arte social moderno. Le muestra cómo la falta de fe en la lucha lo ha llevado al escepticismo que padece a convertirse en "poeta metafísico de la plástica". "Tu actitud, a fin de cuentas pertenece en realidad a resabios del débil romanticismo que conduce a juzgar las flaquezas de los hombres como miserias del movimiento en que éstos actúan." La pérdida de fe en el hombre y en las posibilidades del triunfo de un nuevo humanismo, evidentemente aparece en Orozco. Cargado de escepticismo el pintor del Hospicio Cabañas encamina su comprensión del hombre por el lado de la desesperanza, la amargura, el fuego y la violencia aniquiladora. Esta enfermedad, como llama Siqueiros al nihilismo y la desesperanza de Orozco, "es curable o incurable ... y yo creo que la tuya tiene remedio. Un nuevo florecimiento en la esperanza popular puede tocar otra vez tu enorme fuerza de pintor. Muy lejos de mi pensamiento el considerarte como un viejo mental. Eres, quizá, el más joven de los atacados por la crisis intelectual que hoy se padece". Con la convicción y el cariño al compañero agitador de los primeros años del periódico "La Vanguardia", del ejército constitucionalista, con el reconocimiento a la obra del caricaturista anticlerical, del dibujante social y antifascista de años atrás, previene Siqueiros al maestro jalisciense de estar cayendo en "tendencias que ya no tienen salida histórica posible" y lo insta con cariño y respeto a regresar a la única ruta posible: ". . . en el mundo próximo futuro, el de la postguerra que ya viene [los artistas] o toman el camino nuestro, el camino de un nuevo humanismo en el arte, de un nuevo clasicismo, de un nuevo humanismo -nuevo realista o no van a ninguna parte"."

A pesar de reconocer Siqueiros el inmenso valor que el pintor de Guadalajara mostró al intentar renovar técnicamente la pintura al fresco introduciendo procedimientos novedosos como mezclas de "fresco" y "temple", Siqueiros insiste en el progreso ideológico y técnico del arte y así, pregunta a Orozco: “ ¿Tuviste éxito con el empeño de enriquecer el viejo procedimiento? Yo creo que no, ya que a una nueva sociedad corresponde una nueva técnica, la estricta técnica material de su industria correspondiente".

La obsesión por lograr expresar en términos técnicamente modernos la lucha revolucionaria del hombre contemporáneo, es la tarea monstruosamente ambiciosa que Siqueiros se echa sobre los hombros. Por ello aprovecha e incluye todo : la reproducción gráfica, el uso de los nuevos productos de la química y los plásticos, la pistola de aire, el azulejo o

"David Alfaro Siqueiros, "Carta a Orozco", Revista Hoy, México, núm. 398, oct. 7, 1944. 
mosaico coloreado, la esculto-pintura, el ferrocemento, etcétera. Todos los adelantos modernos de la industria y la tecnología son aprovechados ansiosamente y son usados en un todo que resulta exagerado, abigarrado. En su afán de abarcar y decir al máximo, su obra probablemente resulte excesiva y a veces repelente en su grandilocuencia a menudo grotesca. Si se pregunta desde una concepción cerrada de los cánones estéticos de la cultura occidental ino es grotesca y monstruosa la Coatlicue? Si se compara el barroco europeo con el americano ino rompen cualquier ritmo las estridencias y abundancias de nuestro barroco? ¿Las llamas, las nubes de ángeles, las columnas cambiantes, las abundantes volutas, el horror al vacío, no son muestras del delirio a que llegan las producciones artísticas mexicanas? En las manifestaciones de la cultura popular, más auténticas y enraizadas, se producen ciertas expresiones que para un gusto, un oído, una sensibilidad educada en otras latitudes resultan, si no desagradables, tan ajenas al gusto impuesto que desgarran los sentidos como si se estuviera frente a productos de "la barbarie". Sin embargo, si somos honestos con nuestros gustos americanos podemos olvidarnos de los cánones de belleza que nos han impuesto los europeos como los únicos y verdaderos: la armonía, el refinamiento, el equilibrio, la apariencia medida, la simetría, etcétera. Aún cuando se expresa un alma romántica o expresionista, que para un europeo significa violentar cánones y medidas, para nosotros latinoamericanos siempre se quedan en una tibia exageración que ni di cerca alcanza la desorbitada y sobrecargada éxpresión de lo más auténtico de nuestras culturas, de lo más afín al alma del pueblo, barroco y expresionista por excelencia.

En las producciones de la cultura mexicana ¿no es detemplada y molesta la trompeta del mariachi; el picor del chile que opaca sabores más refinados? ¿no es alarde de rara invención mezclar el chocolate y el cacahuate con los chiles de los moles? Pero ya los poetas estridentistas dijeron: iViva el mole de guajolote! y en él reconocieron a México.

Pero la obra de Siqueiros es otra cosa, o cumple sus propósitos también por caminos diferentes a los del método y la teoría. No es que no sea fiel a los contenidos doctrinarios de sus textos, manifiestos y cartas, sino que los alcanza de manera interior y plena y como desde adentro, como si secretamente acordaran el corazón y la inteligencia en un momento imprevisible y hasta increíble, de no estar ahí las obras mismas como una evidencia que no podemos dejar de lado. Lo que en otros movimientos ar- 
tísticos se convirtió en método, y por ello mismo acabó esterilizando las fuerzas creadoras, como sucedió con el puntillismo, el impresionismo, el cubismo, el futurismo, el surrealismo, y los sucesivos ismos de la escuela europea, sirvió en este caso de fuente de inspiración y fecundamiento. La obra está ahí efectivamente. Desde el punto de vista del espectador participante la primera sensación evidente en una mezcla de repulsión y fascinación.

Quien busque en el arte el deleite de las sensaciones finas y equilibradas no entenderá fácilmente la grandeza de este pintor. Ser contemporáneo de Siqueiros y además mexicano, resulta un doble obstáculo para entenderlo. La contemporaneidad, porque su pintura está nutrida de las realidades cotidianas que quisiéramos olvidar. La nacionalidad, porque de alguna manera pone en juego los resortes del ser mexicano con todas sus grandezas pero sin esconder ninguna de sus aberraciones. Nada nos resulta más insoportable que lo real, y no otra cosa, sino realidad, encontramos en Siqueiros: realidad en los escorzos, con los que avanzan los cuerpos mutilados hasta casi tocarnos; realidad en la perspectiva curva con la que enfrenta todos sus trabajos y que no toleramos precisamente por ser la nuestra, porque nos aleja de la idealización rectilínea del Renacimiento; realidad en el movimiento, que como en las insufribles aporías de Zenón, está y no está en un lugar al mismo tiempo. Pero hay además, acaso, una cierta predilección por el hallazgo de la sangre y el grito. Los ejemplos son innumerables, no valdría la pena traerlos a estas páginas. Aun en las ra ras ocasiones en que intenta naturalezas muertas escoge aquellas frutas que parecieran escarnecidas por la propia naturaleza. En Las Calabazas se adecúa de tal manera el afán de esa pincelada por lo áspero y ocre, lo retorcido y elocuente, que difícilmente podriamos encontrar en la realidad, unos frutos tan perfectos, tan iguales a sí mismos. No falta tampoco el paisaje seco y carcomido del desierto, el polvo que se impone a los cuerpos logra la victoria y el predominio por adelantado, antes de la muerte. Los cielos azules y morados más despedazados y violentos que los del mismo Greco, más cargados de anatemas y violentas amenazas contra el hombre. $Y$ las marchas, las interminables marchas de los pobres: los que van a buscar agua quien sabe a dónde, los que se adelantan para protestar con el rostro convulso de las máscaras, los que buscan la tierra prometida o los que se acompañan simplemente, silenciosamente, seguramente, sin propósito alguno. Todo parece en realidad concebido para mostrar lo frágil de la carne. Ningún fuego más fuego que ése en el que se consumen las plantas de Cuauhtémoc. Ninguna lanza más aguda que la que penetra en la carne recta e infaliblemente. Es como si se buscara retorcer, estrujar, 
macerar, poner a prueba por todos los medios posibles la resistencia de la carne. Evaluar realmente el precio de estar vivos en la tierra.

Quizá en todo gran pintor ha habido siempre este exceso, esta inevitable mala suerte de resultar insoportable a su tiempo precisamente por ser justo y veraz con sus objetos. A fuerza de deformaciones esteticistas acabamos por no ver en realidad los cuadros y sólo vemos las representaciones que los profesores, casi siempre pulcros y bien educados, han impreso en nuestro entendimiento. Porque bien visto, ¿quién soporta en realidad las crucifixiones de los primitivos o el cuadro de la pasión de Hans Memling donde los clavos entran más adentro que nunca en los pies de la víctima, fracturando limpiamente los huesos, o el tríptico de Grunewald que, quizá, debe haber aterrorizado a los campesinos que lo vieron por primera vez, y que ahora nos parece lleno de una composición serena si nos ponemos los anteojos de los institutos de estudios estéticos? ¿No es por otra parte, nuestra época más cruel que todas las anteriores? ¿No estamos más cerca ahora de la extinción de la especie y como al final de todo, y lo que en verdad nos parece proporcionado y armónico no es precisamente aquello que no está en la realidad? La verdad es triste ya 10 decía Voltaire, y más que triste extremosa. No está en el centro, en el justo medio que quería Aristóteles, está en uno de los extremos.

Pero seríamos seguramente injustos si sólo viéramos en Siqueiros el estremecimiento por la lucha y la derrota, por lo que erosiona y por lo que finalmente sucumbe. También en su pintura hay grandeza, y en alguna parte, a pesar de todo, surgen los rostros serenos de los que saben que la victoria será suya finalmente, el gesto heroico de los que asumen su deber, la interminable fila, también, de los que nos apoyan y sostienen con su esfuerzo, su valor y su constancia. Después de todo, cuando Cuauhtémoc se levanta, viste la armadura del conquistador y libera a su pueblo. En el cielo de las cúpulas que no quisieron quizá nunca entregar el secreto de sus perspectivas se cruzan las contrucciones de los hombres. La vida tiene un sentido y la humanidad marcha hacia adelante; no es casualidad que su obra más entrañablemente sentida y diseñada se titule así. Hay también en Siqueiros la certeza del triunfo. Ningún genio maligno, ninguna línea de producción en serie, ninguna lanza, ningún fuego, podrán vencer al hombre, derrotar al pueblo.

Pero acaso hasta ahora hemos hablado, por decirlo así, de la parte exterior de su pintura, de su manera y algunos de sus temas. Y no es eso lo que en realidad nos sobrecoge de ella, lo que nos repele y atrae. Hay otro modo más constante y tenaz con el que esa pintura nos perturba y en lo que reside y funda al mismo tiempo su triunfo y predominio. No sé si 
alguien pueda contemplar el autorretrato de Siqueiros El coronelazo, (1945) sin sentir en alguna medida repugnancia. No es seguramente una de sus obras más logradas pero, quizá por ser él mismo el tema, contiene claves más evidentes para entender su pintura. Se trata del cuadro aquél en que la mano se adelanta en una especie de escorzo insostenible y en un ademán violento parece restregar y herir los nudillos contra un primer plano impreciso, situado más acá, fuera del cuadro. Como si el brazo y la mano hubieran salido de la tela o, mejor aún, como si rozaran el cristalino mismo del espectador, lastimándose ahí, dejando fragmentos de piel y sangre. No pasemos ahora a calificar el ademán y el gesto ni la idea que de sí mismo pudo haber tenido Siqueiros. Pero algo queda ahí que nos atrae y abisma, quizá en ninguno de sus cuadros se suceden tan rápidamente la repulsión y la fascinación. Ninguno está construído más deliberadamente para molestar al espectador y al mismo tiempo para imponerse sobre él, para vencerlo. No es un mal cuadro tampoco, porque entre otras cosas, así era en lo personal Siqueiros, parecía, como en la escena final del Retrato del artista adolescente, estar siempre arrojando al aire un puñado de guisantes. Pero sea como sea ahí están esos nudillos restregados contra no se qué, adelantados contra su espacio natural, lastimándose en un vidrio invisible, llenos de la velocidad de la destrucción, perecederos y débiles, de carne, como diciéndonos algo, como recordándonos un mensaje antiguo y persistente.

Suele decirse injustamente que nuestros pueblos, los americanos, son crueles. Como si de alguna manera encarnáramos, por los sacrificios humanos, una manera de ser opuesta a los principios y acciones de la civilización occidental. En realidad es difícil imaginar una crueldad más grande que la de los propios occidentales que matan y torturan sin ningún miramiento para sostener un orden injusto o para extenderlo. Pero no podemos negar tampoco que haya en nosotros, quizá en todos los hombres, un instinto de lucha y de crueldad que de alguna manera es parte de la naturaleza humana, por lo menos de la que conocemos hasta ahora. En los aztecas, el sacrificio humano no se realizaba por mezquinas conveniencias pecuniarias. Los sacrificios revitalizaban con su sangre el oro del sol y permitían que la vida continuara a través de renacimientos incesantes. La carne es débil, es cierto, y la crueldad tal vez no sea sino una manera de experimentar y entenderla. Esos nudillos que se adelantan y rompen contra la realidad recuerdan la piel de los desollados que los antiguos sacerdotes vestían en ciertas ceremonias como si una segunda piel pudiera revestir de inmortalidad a la débil por la que vivimos y perecemos. Mediante el sacrificio y el desollamiento se rompía el orden de los cuerpos en un su- 
premo esfuerzo por restablecer el orden del universo. En el autorretrato, desde ese rostro que lleva hacia adelante la mano crispada con sus nudillos heridos hay un desafío también, como si la lucha fuera un ingrediente indispensable de la libertad. Destruir para construir parecería ser la intención de los sacerdotes. Nada extraño por cierto que la hostia y el cáliz de la comunión sean la carne y la sangre de Jesucristo. Hay en la destrucción un desafío contra el orden, contra lo establecido, contra sí mismo. Un pueblo que sabe desafiar es un pueblo que sabe también liberarse. No es casual que México, ha dicho alguien, sea el país de las tres revoluciones.

Lo que finalmente parece querer decirnos Siqueiros es que la lucha y el desafío están necesariamente en la esencia revolucionaria que toda revolución tiene que ser, en alguna forma, violenta. Y que aquello en lo que encontramos mayor debilidad, la carne, es también lo que se rebela y avanza, lo que finalmente siempre encuentra el camino de la liberación, de la revolución y la victoria.

Pero Siqueiros no se detiene en esta mera exaltación de la violencia y la crueldad que algunos escritores como D. H. Lawrence y Octavio Paz, han creído encontrar en la esencia de la mexicanidad. En el fondo hay mucha más ternura que crueldad en su obra y más esperanza en la subversión y la victoria que en la confianza que aquellos literatos tienen en la derrota. 